\title{
Outcomes in randomised controlled trials of multifocal lenses in cataract surgery: the case for development of a core outcome set
}

\author{
Jennifer R Evans (D) ,' Samantha R de Silva (D) , ${ }^{2}$ Mohammed Ziaei (D) , ${ }^{3}$ \\ Varo Kirthi (D) ${ }^{4}$ Martin D Leyland ${ }^{5}$
}

- Additional material is published online only. To view please visit the journal online (http://dx.doi.org/10.1136/ bjophthalmol-2019-315410).

${ }^{1}$ International Centre for Eye Health, London School of Hygiene and Tropical Medicine, London, UK

${ }^{2}$ Oxford Eye Hospital, Oxford, UK

${ }^{3}$ Department of Ophthalmology, New Zealand National Eye Centre, University of Auckland, Auckland, New Zealand

${ }^{4}$ Department of Ophthalmology, King's College Hospital,

London, UK

${ }^{5}$ Department of Ophthalmology, The Royal Berkshire NHS Foundation Trust, Reading, UK

\section{Correspondence to} Dr Jennifer R Evans, International Centre for Eye Health, London School of Hygiene and Tropical Medicine, London WC1E 7HT, UK; jennifer.evans@lshtm.ac. uk

Received 18 October 2019 Revised 12 December 2019 Accepted 14 December 2019
Check for updates

(C) Author(s) (or their employer(s)) 2020. No commercial re-use. See rights and permissions. Published by BMJ.

To cite: Evans JR, de Silva

$\mathrm{SR}$, Ziaei $\mathrm{M}$, et al. Br J

Ophthalmol

2020:104:1345-1349.

\section{ABSTRACT \\ Background/aims To describe and summarise the outcomes reported in randomised controlled trials of multifocal versus monofocal intraocular lenses in cataract surgery.}

Methods We identified all randomised controlled trials of multifocal versus monofocal lenses in a Cochrane review (last search date June 2016). We extracted and summarised data on all outcomes reported using the framework of domain, measurement, metric and method of aggregation.

Results All studies collected data on distance and near visual acuity but there was considerable variation in the measures used and whether these outcomes were unaided or best corrected. Most studies reported final value measurements, rather than change from baseline. Approximately half of the studies reported data as a continuous measure only, one-third reported both continuous and categorical measures and a minority reported categorical measures only. There was little consensus as to cut-points. Although a majority of studies included one or more patient-reported outcome measures, none of the studies reported patient involvement in the choice of outcomes.

Conclusion The collection and analysis of data on outcome measures in studies of multifocal intraocular lenses in cataract surgery are complicated. As a result, there is considerable heterogeneity in collection and reporting in the medical literature. This makes it difficult to synthesise such data to provide robust estimates of effect and is a potential source of research waste. Investigators in this field must produce a core outcome set that is informed by patients' views and we propose an initial set of outcomes on which these could be based.

\section{INTRODUCTION}

An estimated 53 million people worldwide are visually impaired due to cataract. ${ }^{1}$ Cataract surgery is one of the most commonly performed operations in the world, with around 330000 cataract operations performed per year in England alone. ${ }^{2}$

The most frequently used replacement intraocular lens (IOL) usually has one focal length (monofocal), and usually corrects vision after cataract surgery for distance, for example, driving and viewing television, but not necessarily for near vision tasks, such as reading and seeing the computer. In order to achieve good near vision, an additional pair of spectacles after cataract surgery may be required.
Multifocal lenses can potentially overcome this difficulty by providing more than one focal distance; this may increase the chances of spectacle freedom following cataract surgery. However, multifocal lenses may be associated with more visual problems, for example, glare, starbursts and haloes (rings around lights). ${ }^{3}$

Randomised controlled trials can provide good quality evidence of risks and benefits of these IOLs. We have published an updated Cochrane systematic review comparing multifocal versus monofocal lenses. ${ }^{3}$ As part of this review, we identified all the published randomised controlled trials of multifocal compared with monofocal lenses. Systematic reviews can provide more precise estimates of effect by pooling data from trials reporting the same outcome, thereby increasing the sample size and narrowing the CIs around the effect estimates. The usefulness of such a review is critically dependant on the included trials reporting the same outcomes. $^{4}$

The Cochrane review included 20 relevant trials that enrolled 2230 people with data available on 2061 people (3194 eyes). The majority (18) of these trials compared multifocal lenses to monofocal lenses and two studies compared multifocal lenses to 'monovision' (monofocal lenses of different focal length in each eye). We extracted data based on prespecified outcomes for meta-analysis. The median number of studies reporting data on each prespecified outcome in the review was 4 (range 1-10). If all the studies had reported the same outcomes, in a similar format, each analysis would have had 18 trials contributing data (for the multifocal vs monofocal comparison, for example). The review, potentially, could have been more conclusive. We used Grading of Recommendations Assessment, Development and Evaluation to assess the certainty of the data ${ }^{5}$ and downgraded much of the evidence due to imprecision. In addition, it was largely unclear if the data that were unreported were selectively omitted. ${ }^{6}$

The aim of the current paper is to describe all the outcomes published in these trials, not just the outcomes prespecified and reported in our Cochrane review, with a view to making suggestions for a set of core outcomes for this topic. ${ }^{7}$ In particular, we were interested in the reporting and analysis of visual acuity and contrast sensitivity data. We also planned to assess whether the outcomes reported have changed over time. 


\begin{tabular}{lll}
\hline Table 1 & Outcome domains reported & \\
\hline Domain & $\begin{array}{l}\text { Number of studies } \\
\text { reporting }\end{array}$ & $\begin{array}{l}\text { Percentage of studies } \\
\text { reporting }\end{array}$ \\
\hline Distance visual acuity & 20 & 100 \\
Intermediate visual acuity & 4 & 20 \\
Near visual acuity & 20 & 100 \\
Contrast sensitivity & 14 & 70 \\
$\begin{array}{l}\text { Patient-reported outcome } \\
\text { measure (PROM) }\end{array}$ & 16 & 80 \\
\begin{tabular}{l} 
Spectacle independence \\
\hline
\end{tabular} & 12 & 60 \\
\hline
\end{tabular}

\section{MATERIALS AND METHODS Included studies}

We included randomised controlled trials comparing a multifocal IOL of any type with a monofocal IOL. Both unilateral and bilateral implantation trials were included. We also considered trials comparing multifocal IOLs with monovision.

\section{Search strategy}

We searched CENTRAL (which contains the Cochrane Eyes and Vision Trials Register) (2016, Issue 5), Ovid MEDLINE, Ovid MEDLINE In-Process and Other Non-Indexed Citations, Ovid MEDLINE Daily, Ovid OLDMEDLINE (January 1946 to June 2016), Embase (January 1980 to June 2016), the ISRCTN registry (www.isrctn.com/editAdvancedSearch), ClinicalTrials.gov (www.clinicaltrials.gov) and the WHO International Clinical Trials Registry Platform (ICTRP) (www.who.int/ictrp/search/en). We did not use any date or language restrictions in the electronic searches for trials. We last searched the electronic databases on 13 June 2016. The full search strategy is available here. ${ }^{3}$ Two authors screened studies independently for relevant trials. We resolved disagreements by discussion.

\section{Data collection}

We extracted the following information from the included trials onto an Excel spreadsheet. Data were extracted independently by two authors (pairs of JRE, MZ, KV and SdeS).

Study-level data

- Study name.

- Date conducted.

- Location.

- Were patients involved in choice of outcomes?

- Parallel group/within-person study.

- Bilateral/unilateral surgery.

\section{Outcome-level data}

We followed the terminology used by Zarin et $a l^{8}$ to classify outcome data. This has been used previously in an assessment of Cochrane Eyes and Vision systematic reviews. ${ }^{9}$

- Domain (eg, distance visual acuity).

- Specific measurement.

- Chart (eg, ETDRS visual acuity chart).

- Distance (eg, $4 \mathrm{~m}$ distance).

- Lighting (eg, photopic conditions).

- Specific metric (eg, change from baseline).

- Method of aggregation (eg, mean).

We also collected data on:

- Timepoint (eg, 12 months).

- Eyes-monocular/binocular.

\section{Data analysis}

We tabulated the collected data and provide a descriptive summary. We grouped the data on date conducted in 5-year bands.

\section{RESULTS}

\section{Description of studies}

We included 20 studies. ${ }^{10-29}$ These studies took place over a 21year period, largely in the European region (see online supple mentary table 1). None of the studies reported patient involvement in the choice of outcomes. There was a mixture of unilateral surgery $(40 \%)$ and bilateral surgery $(50 \%)$ with $10 \%$ of studies reporting both. Follow-up duration varied from immediately postoperative (two studies, complications) to 18 months (one study) (see online supplementary table 2).

\section{Domains reported}

All studies reported distance and near visual acuity (table 1). Very few studies reported intermediate visual acuity. Contrast sensitivity and patient-reported outcome measures (PROM), including spectacle independence, were reported by the majority, but not all, studies.

\section{Measures of visual acuity and contrast sensitivity}

Distance visual acuity

Most studies (18/20) reported unaided distance visual acuity (table 2). Fourteen out of 20 studies reported best corrected visual acuity, five studies reported other corrections-either spectacle corrected (three studies), presenting (with/without spectacles), or unclearly reported.

Intermediate visual acuity

Three of the four studies that documented intermediate visual acuity reported unaided intermediate visual acuity; two of these

Table 2 Measures of visual acuity and contrast sensitivity

\begin{tabular}{|c|c|c|c|c|}
\hline Number of studies reporting & $\begin{array}{l}\text { Distance } \\
(\mathrm{n}=20)\end{array}$ & $\begin{array}{l}\text { Intermediate } \\
(n=4)\end{array}$ & $\begin{array}{l}\text { Near } \\
(n=20)\end{array}$ & $\begin{array}{l}\text { Contrast sensitivity } \\
(n=14)\end{array}$ \\
\hline Unaided & 18 & 3 & 18 & 2 \\
\hline $\begin{array}{l}\text { Best corrected } \\
\text { (for distance) }\end{array}$ & 14 & 2 & 9 & 1 \\
\hline Best corrected (for near) & & & 7 & \\
\hline Best spectacle corrected & 3 & & & 3 \\
\hline $\begin{array}{l}\text { Presenting (with/without prescribed } \\
\text { spectacles) }\end{array}$ & 1 & & 1 & \\
\hline Other & $\begin{array}{l}\text { Corrected but not } \\
\text { specified how } \\
\text { (1 study) }\end{array}$ & $\begin{array}{l}-1.25 \\
\text { D addition } \\
\text { (1 study) }\end{array}$ & $\begin{array}{l}\text { Distance vision plus } 2.75 \text { reading additions } \\
\text { Plus }-2.5 \text { D 'with near correction' } \\
\text { Distance refraction with addition unspecified }\end{array}$ & $\begin{array}{l}\text { Unclear or not reported (8 studies) } \\
\text { Plus } 2.75 \text { D when testing near } \\
\text { contrast sensitivity (1 study) }\end{array}$ \\
\hline
\end{tabular}




\begin{tabular}{|c|c|c|c|c|}
\hline Number of studies reporting & Distance $(n=20)$ & $\begin{array}{l}\text { Intermediate } \\
(\mathrm{n}=4)\end{array}$ & $\begin{array}{l}\text { Near } \\
(n=20)\end{array}$ & $\begin{array}{l}\text { Contrast sensitivity } \\
(n=14)\end{array}$ \\
\hline Snellen & 9 & 2 & & \\
\hline LogMAR & 7 & 2 & 4 & \\
\hline Regan $96 \%$ contrast chart & 2 & & & 2 \\
\hline Jaeger reading chart & & & 6 & \\
\hline Rosenbaum near acuity card & & & 3 & \\
\hline Sloan letters near acuity chart & & & 2 & \\
\hline Pelli-Robson contrast sensitivity chart & & & & 6 \\
\hline Vision Contrast Test System & & & & 4 \\
\hline Other & & & $\begin{array}{l}\text { De Nederlanders ( } 1 \text { study) } \\
\text { Salzburg reading desk (1 study) }\end{array}$ & $\begin{array}{l}\text { CGT-1000 contrast sensitivity instrument (1 study) } \\
\text { FACT chart/OPTEC } 6500 \text { ( } \text { study) }\end{array}$ \\
\hline Chart not specified or unclearly specified & 2 & & 3 & \\
\hline
\end{tabular}

FACT, Functional Acuity Contrast Test.

studies reported intermediate visual acuity with best distance correction.

\section{Near visual acuity}

Most studies reported unaided near visual acuity. Nine studies reported near visual acuity with best distance correction, seven reported with best near correction, one study reported presenting near acuity (with or without prescribed spectacles) and three studies reported near acuity corrected for distance visual acuity but with a near addition.

\section{Contrast sensitivity}

A total of 14 studies reported contrast sensitivity. In just over half of studies the correction was not specified or unclear (eight studies). Two studies stated that contrast sensitivity was tested unaided, one study that this was best corrected and three studies that this was best spectacle corrected.

\section{Testing conditions}

\section{Visual acuity test charts}

The most commonly used visual acuity test chart was Snellen (nine studies), followed by logMAR (seven studies) (table 3). Two studies used the Regan $96 \%$ contrast chart, and in two studies the chart was not clearly specified. Intermediate visual acuity was measured using either Snellen (two studies) or logMAR charts (two studies). A wider variety of tests were used to measure near acuity including Jaeger charts (six studies), logMAR charts (four studies), Rosenbaum near acuity card (three studies), Sloan letters near acuity chart (two studies), and the De Nederlanders chart (one study) and Salzburg reading desk. Three studies did not specify the chart clearly. PelliRobson contrast sensitivity chart was the most commonly used method of measuring contrast sensitivity (six studies), followed by the Vision Contrast Test System (four studies), Regan 96\% contrast chart (two studies), CGT-1000 contrast sensitivity instrument (one study) and Functional Acuity Contrast Test chart/OPTEC 6500 (1 study).

\section{Distance at which visual acuity was measured}

Most studies did not report the distance at which distance visual acuity was measured (nine studies), the most commonly reported distance was $4 \mathrm{~m}$ (five studies); two studies measured at $6 \mathrm{~m}$, two at $5 \mathrm{~m}$ and one at $3 \mathrm{~m}$. The four studies reporting intermediate visual acuity all reported at different distances-one study at $80 \mathrm{~cm}$, one study at $1 \mathrm{~m}$, one study at three distances-70,60 and $50 \mathrm{~cm}$ - and one study did not specify the distance. Distance was specified more commonly for near visual acuity but there was as wide variety of distances reported $-33 \mathrm{~cm}$ (two studies), $35 \mathrm{~cm}$ (two studies), $35-46 \mathrm{~cm}$ (one study), $26 \mathrm{~cm}$ (one study), $40 \mathrm{~cm}$ (five studies). Nine studies did not report the distance, but of these nine studies, one used the patient's preferred reading distance (and corrected the score), one reported the preferred reading distance as an outcome and one reported '... the reading addition necessary to read $\mathrm{J} 2$ at $25 \mathrm{~cm}$ ' as an outcome. Three studies measured contrast sensitivity at $1 \mathrm{~m}$ and one study normalised to a $10 \mathrm{ft}$ test distance (probably measured at 8 and $10 \mathrm{ft}$ ). The remaining 10 studies did not report the distance at which contrast sensitivity was measured.

\section{Lighting}

The lighting used to measure distance visual acuity was not described in most studies. Two studies reported they used photopic conditions (in one study this was stated to be approximately 85 candelas $(\mathrm{cd}) / \mathrm{m}^{2}$ ). One study used the ACP-8 Auto Chart Projector. One study specified three light levels (three light levels 1-3 foot-candles (ft-c; night driving, no glare), 20-70 ft-c (normal indoor lighting) and full midday sunshine and glare (Brightness Acuity Tester (BAT) at medium)). In the four studies of intermediate visual acuity, lighting was not specified in two studies, was photopic $\left(85 \mathrm{~cd} / \mathrm{m}^{2}\right)$ in one study and $6 \mathrm{~cd} / \mathrm{m}^{2}$ in one study. For near acuity, photopic conditions were used in three studies (not defined, 85 and $80 \mathrm{~cd} / \mathrm{m}^{2}$ ) and mesopic conditions in two studies ( 5 and $6 \mathrm{~cd} / \mathrm{m}^{2}$ ), one study used three levels of lighting (as for distance visual acuity), one study used a $40 \mathrm{~W}$ bulb with overhead lights off and one study used 500 lux (may apply to all visual acuity measurements). In 13 studies it was not clear what lighting was used.

\section{Metric and method of aggregation}

Most studies reported final value for distance, intermediate, near visual acuity and contrast sensitivity (see online supplementary table 3). Only one study reported both final value and change from baseline. Most studies reported visual acuity measures as a continuous variable: for distance visual acuity 16/20 studies, for intermediate visual acuity $3 / 4$ studies, for near visual acuity $13 / 20$ studies and for contrast sensitivity all 14 studies reporting this outcome. All continuous variables were reported as means, one study reported both means and medians. There was a wide variety of categorical cut-points used. 


\begin{tabular}{lcc}
\hline Table 4 & Type of patient-reported outcome measure (PROM) \\
\hline Name of PROM & $\begin{array}{l}\text { Number of } \\
\text { studies }\end{array}$ & Percentage \\
\hline $\begin{array}{l}\text { Able to manage activities of daily living without } \\
\text { glasses }\end{array}$ & 1 & 5 \\
Cataract Symptom Score & 2 & 10 \\
\hline Cataract TyPE Questionnaire & 1 & 5 \\
\hline Modified Cataract TyPE Questionnaire & 1 & 5 \\
\hline Modified V7 questionnaire & 1 & 5 \\
\hline Rasch-scaled VF-11 (VF-11R) scores used after & 1 & 5 \\
removing 3 questions from VF-14 & 1 & 5 \\
\hline Self-reported overall health (0-10) & 2 & 10 \\
\hline Self-reported rating of vision & 10 & 50 \\
\hline Self-reported satisfaction & 1 & 5 \\
\hline Self-reported satisfaction with vision after surgery & & \\
\hline Spectacle independence & 2 & 10 \\
\hline$\quad$ VF-14 & 2 & 10 \\
\hline VF-7 & 1 & 5 \\
\hline VQOL (vision-related quality of life) & 14 & 70 \\
\hline Visual symptoms (glare, haloes, and so on) & 1 & 5 \\
\hline Would patients choose the same IOL again? & & \\
\hline
\end{tabular}

IOL, intraocular lens.

Online supplementary table 4 shows how the included studies dealt with the analysis of eyes and people. None of the studies that reported by eye included an appropriate adjustment for within-person correlation. Approximately half of studies with a unilateral study design did not clearly state this in the report.

\section{Patient-reported outcome measures}

A variety of PROMs were used (table 4). A number of studies used validated questionnaires (VF-7, VF-14, Cataract TyPE Questionnaire, Cataract Symptom Score), and modifications thereof, but each individual questionnaire was only used by one or two studies each. Although half of studies collected data on 'selfreported satisfaction' there was almost no agreement on how this should be collected. Most studies used some form of Likert scale with either 3,5 or 10 categories. The wording associated with this Likert scale varied with different studies assessing different but related constructs: 'satisfaction' (eg, very dissatisfied to very or highly satisfied), 'quality' (eg, poor to excellent) or 'impact' (eg, incapacitating to excellent).

The majority of studies assessed visual symptoms such as glare/ haloes. In most studies it was clear what 'presence/absence' was but some studies graded using a Likert scale and analysed as a quantitative measure (see online supplementary table 5). Some studies measured the effect of glare using the Brightness Acuity Tester, reporting visual acuity and contrast sensitivity with and without glare. There was inconsistency as to whether glare or glare disability was assessed. One study measured the effect of glare on a number of different activities.

Spectacle independence was assessed in most but not all studies. Again, there was considerable variability in how this was measured and reported (see online supplementary table 6).

\section{Other outcomes}

A variety of other outcomes were reported (see online supplemen tary table 7).

\section{DISCUSSION}

This study has documented considerable heterogeneity in data collection and reporting of outcomes when comparing multifocal to monofocal lenses. This variability highlights the confusion evident as to what outcomes are important to study when conducting trials in this field. We have probably underestimated the variability for some domains: for example, the use of Jaeger charts for near vision testing is probably even more inconsistent than appears in this report because the $J$ scale is not standardised and so differs between manufacturers. ${ }^{30}$ It is also likely that lighting conditions, which were inconsistently documented in the studies, may also vary between studies.

It is notable that no patients were apparently consulted when doing these studies, especially since one of the main concerns regarding the use of multifocal lenses are subjective symptoms such as the presence of glare and haloes. Although we limited ourselves to randomised controlled trials identified in our Cochrane review for which the searches were done in 2016, an assessment of a selection of randomised controlled trials done after that time ${ }^{31-33}$ (identified on PubMed) does not suggest that any improvement had occurred since, with little systematic consideration of how outcomes are selected and analysed and little evidence of patient involvement in the choice of outcomes.

The impact of such variability is considerable research waste because it is difficult to compare the results of such studies and synthesise appropriately to provide an overall estimate of effect in a meta-analysis. ${ }^{3}$ Chalmers and Glasziou have highlighted recently the huge avoidable waste in clinical research, estimated about $\$ 100$ billion annually. ${ }^{34}$ It also means that, as systematic reviewers, we are unable to address effectively the extent to which selective reporting of outcomes occurs in this field.

The solution to this problem is conceptually simple but requires funding and collaboration. Prior to starting a new clinical trial, investigators need to consider carefully which outcomes should be collected and analysed. Ideally this would involve collaboration to develop a core outcome set and will include patients' views. ${ }^{7}$ There is considerable experience in how to develop core outcome sets ${ }^{35}$ but ophthalmic researchers have been slow to adopt them. We are aware of one proposed minimum set of outcome measures for cataract surgery. ${ }^{36}$ However, this was developed with healthcare professionals, rather than researchers, in mind. There were potentially some important omissions, for example, near visual acuity, spectacle independence and visual symptoms were not adequately addressed. The report also did not give any guidance on reporting of the outcomes, which can make a difference to the extent to which any trials' findings may be incorporated in a systematic review.

Prespecification of a core outcome set and providing a strategy for analysis in a publicly available protocol would be an important step to eliminating problems of selective outcome reporting ${ }^{6}$ which is common in medical research. ${ }^{37}$ Importantly, it would allow a much more efficient use of the data collected and the resources (both health funding and patient time) involved.

Based on our analysis of the studies included in our Cochrane review, in which all studies reported distance and near visual acuity and most studies reported contrast sensitivity and PROMs, we propose an initial set of outcomes that could form the basis of the development of a core outcome set (table 5). We would suggest that these variables are measured at a postoperative visit between 6 and 18 months after surgery (metric: final value) and where possible binocular measures are also documented. This is a proposed minimum set of outcomes that would be measured and reported in every trial; this does not restrict trialists- they would be free to measure any number of additional outcomes. However, if all trials reported this minimum set, in this format, this would be an important step for future systematic reviews. This list is based on our experience of undertaking a Cochrane review and collecting data on the outcomes 
Table 5 Proposed outcomes to form the basis for a core outcome set for studies of multifocal lenses in cataract surgery

\begin{tabular}{|c|c|c|}
\hline Domain & Specific measurement & Method of aggregation \\
\hline Distance visual acuity & $\begin{array}{l}\text { LogMAR chart, with and } \\
\text { without usual spectacles }\end{array}$ & Mean \\
\hline Near visual acuity & $\begin{array}{l}\text { LogMAR chart, with and } \\
\text { without usual spectacles }\end{array}$ & Mean \\
\hline Contrast sensitivity & $\begin{array}{l}\text { Pelli-Robson chart, with } \\
\text { and without usual } \\
\text { spectacles }\end{array}$ & Mean \\
\hline Spectacle independence & $\begin{array}{l}\text { Questionnaire, overall, } \\
\text { distance and near } \\
\text { separately }\end{array}$ & $\begin{array}{l}\text { Proportion of people } \\
\text { spectacle free, that is, do not } \\
\text { need to use spectacles for } \\
\text { any task }\end{array}$ \\
\hline Quality of life & $\begin{array}{l}\text { Questionnaire: ideally VF-7 } \\
\text { or VF-14 }\end{array}$ & Mean \\
\hline $\begin{array}{l}\text { Visual symptoms, for } \\
\text { example, glare haloes }\end{array}$ & $\begin{array}{l}\text { Questionnaire: glare, } \\
\text { haloes and other visual } \\
\text { symptoms }\end{array}$ & $\begin{array}{l}\text { Proportion of people with } \\
\text { visual symptoms, each } \\
\text { symptom reported separately }\end{array}$ \\
\hline
\end{tabular}

used in these trials. The final choice of core outcomes should ideally be chosen by means of wider consultation, including trialists and patients, and using recognised method of establishing consensus, for example, using a Delphi survey. ${ }^{38}$ Development of a core outcome set for cataract surgery will only be successful if there is genuine effort to achieve consensus with professional organisations, patient groups and key opinion leaders, in the choice, specification and dissemination of these outcomes.

Contributors JRE conceived the idea for this paper in discussion with all coauthors, coordinated the data collection and analysis and wrote the first draft of the paper. SdeS, MZ and KV collected the data. All authors revised the manuscript critically for important intellectual content and gave final approval of the manuscript.

Funding The authors have not declared a specific grant for this research from any funding agency in the public, commercial or not-for-profit sectors.

Competing interests None declared.

Patient consent for publication Not required.

Provenance and peer review Not commissioned; externally peer reviewed.

Data availability statement Data are available upon reasonable request.

ORCID iDs

Jennifer R Evans http://orcid.org/0000-0002-6137-2030

Samantha R de Silva http://orcid.org/0000-0002-4455-2814

Mohammed Ziaei http://orcid.org/0000-0002-1289-3796

Varo Kirthi http://orcid.org/0000-0003-4322-1017

\section{REFERENCES}

1 Flaxman SR, Bourne RRA, Resnikoff $S$, et al. Global causes of blindness and distance vision impairment 1990-2020: a systematic review and meta-analysis. Lancet Glob Health 2017;5:e1221-34.

2 Day AC, Donachie PH, Sparrow JM, et al. Royal College of ophthalmologists' national ophthalmology D. the Royal College of ophthalmologists' national ophthalmology database study of cataract surgery: report 1, visual outcomes and complications. Eye 2015;29:552-60

3 de Silva SR, Evans JR, Kirthi V, et al. Multifocal versus monofocal intraocular lenses after cataract extraction. Cochrane Database of Systematic Reviews 2016;115.

4 Kirkham JJ, Altman DG, Chan A-W, et al. Outcome reporting bias in trials: a methodological approach for assessment and adjustment in systematic reviews. BMJ 2018;362.

5 Guyatt $\mathrm{GH}$, Oxman $\mathrm{AD}$, Vist $\mathrm{GE}$, et al. Grade: an emerging consensus on rating quality of evidence and strength of recommendations. BMJ 2008;336:924-6.

6 Dwan K, Altman DG, Arnaiz JA, et al. Systematic review of the empirical evidence of study publication bias and outcome reporting bias. PLoS One 2008:3:e3081.

7 Williamson P, Clarke M. The comet (core outcome measures in effectiveness trials) initiative: its role in improving Cochrane reviews. The Cochrane database of systematic reviews 2012;5

8 Zarin DA, Tse T, Williams RJ, et al. The ClinicalTrials.gov results database--update and key issues. N Engl J Med 2011;364:852-60.
9 Saldanha IJ, Dickersin K, Wang X, et al. Outcomes in Cochrane systematic reviews addressing four common eye conditions: an evaluation of completeness and comparability. PLoS One 2014;9:e109400.

10 Cillino S, Casuccio A, Di Pace F, et al. One-Year outcomes with new-generation multifocal intraocular lenses. Ophthalmology 2008;115:1508-16.

11 el-Maghraby A, Marzouky A, Gazayerli E, et al. Multifocal versus monofocal intraocular lenses. visual and refractive comparisons. J Cataract Refract Surg 1992;18:147-52.

12 Haaskjold E, Allen ED, Burton RL, et al. Contrast sensitivity after implantation of diffractive bifocal and monofocal intraocular lenses. J Cataract Refract Surg 1998:24:653-8.

13 Harman FE, Maling S, Kampougeris G, et al. Comparing the 1CU accommodative, multifocal, and monofocal intraocular lenses. Ophthalmology 2008;115:993-1001.

14 Javitt JC, Steinert RF. Cataract extraction with multifocal intraocular lens implantation: a multinational clinical trial evaluating clinical, functional, and quality-of-life outcomes. Ophthalmology 2000;107:2040-8.

$15 \mathrm{Ji}$ J, Huang X, Fan X, et al. Visual performance of ACRYSOF ReSTOR compared with a monofocal intraocular lens following implantation in cataract surgery. Exp Ther Med 2013;5:277-81.

16 Jusufovic V, Sarajlic D, Zvornicanin J, et al. Comparison of the binocular vision quality after implantation of monofocal and multifocal intraocular lenses. Acta Medica Saliniana 2011:40:63-8.

17 Kamlesh M, Dadeya S, Kaushik S. Contrast sensitivity and depth of focus with aspheric multifocal versus conventional monofocal intraocular lens. Can J Ophthalmol 2001:36:197-201.

18 Labiris G, Giarmoukakis A, Patsiamanidi M, et al. Mini-monovision versus multifocal intraocular lens implantation. J Cataract Refract Surg 2015:41:53-7.

19 Leyland MD, Langan L, Goolfee F, et al. Prospective randomised double-masked trial of bilateral multifocal, bifocal or monofocal intraocular lenses. Eye 2002;16:481-90.

20 Nijkamp MD, Dolders MGT, de Brabander J, et al. Effectiveness of multifocal intraocular lenses to correct presbyopia after cataract surgery. Ophthalmology 2004;111:1832-9.

21 Palmer AM, Faiña PG, Albelda AE, et al. Visual function with bilateral implantation of monofocal and multifocal intraocular lenses: a prospective, randomized, controlled clinical trial. J Refract Surg 2008;24:257-64.

22 Peng C, Zhao J, Ma L, et al. Optical performance after bilateral implantation of apodized aspheric diffractive multifocal intraocular lenses with $+3.00-D$ addition power. Acta Ophthalmol 2012:90:e586-93.

23 Percival SP, Setty SS. Prospectively randomized trial comparing the pseudoaccommodation of the AMO array multifocal lens and a monofocal lens. J Cataract Refract Surg 1993:19:26-31.

24 Rasp M, Bachernegg A, Seyeddain O, et al. Bilateral reading performance of 4 multifocal intraocular lens models and a monofocal intraocular lens under bright lighting conditions. J Cataract Refract Surg 2012;38:1950-61.

25 Rossetti L, Carraro F, Rovati M, et al. Performance of diffractive multifocal intraocular lenses in extracapsular cataract surgery. I Cataract Refract Surg 1994:20:124-8

26 Sen HN, Sarikkola A-U, Uusitalo RJ, et al. Quality of vision after AMO array multifocal intraocular lens implantation. J Cataract Refract Surg 2004:30:2483-93.

27 Steinert RF, Post CT, Brint SF, et al. A prospective, randomized, double-masked comparison of a zonal-progressive multifocal intraocular lens and a monofocal intraocular lens. Ophthalmology 1992:99:853-61.

28 Wilkins MR, Allan BD, Rubin GS, et al. Randomized trial of multifocal intraocular lenses versus monovision after bilateral cataract surgery. Ophthalmology 2013; 120:2449-55.

29 Zhao G, Zhang J, Zhou Y, et al. Visual function after monocular implantation of apodized diffractive multifocal or single-piece monofocal intraocular lens randomized prospective comparison. J Cataract Refract Surg 2010;36:282-5.

30 Bailey I. Specification of near point performance. Optometric monthly 1978:134-7.

31 Cochener B, Boutillier G, Lamard M, et al. A comparative evaluation of a new generation of diffractive Trifocal and extended depth of focus intraocular lenses J Refract Surg 2018;34:507-14.

32 Maxwell A, Holland E, Cibik L, et al. Clinical and patient-reported outcomes of bilateral implantation of a +2.5 diopter multifocal intraocular lens. J Cataract Refract Surg 2017:43:29-41.

33 Schrecker J, Langenbucher A. Visual performance in the long term with secondary add-on versus primary capsular bag multifocal intraocular lenses. J Refract Surg 2016;32:742-7.

34 Chalmers I, Glasziou P. Research waste is still a scandal—an essay by Paul Glasziou and lain Chalmers. BMJ evidence-based medicine 2018;363.

35 Williamson PR, Altman DG, Blazeby JM, et al. Developing core outcome sets for clinical trials: issues to consider. Trials 2012:13:132.

36 Mahmud I, Kelley T, Stowell C, et al. A proposed minimum standard set of outcome measures for cataract surgery. JAMA Ophthalmol 2015;133:1247-52.

37 Goldacre B, Drysdale H, Dale A, et al. Compare: a prospective cohort study correcting and monitoring 58 misreported trials in real time. Trials 2019:20:118.

38 Gorst SL, Gargon E, Clarke M, et al. Choosing important health outcomes for comparative effectiveness research: an updated review and user survey. PLoS One 2016;11:e0146444. 